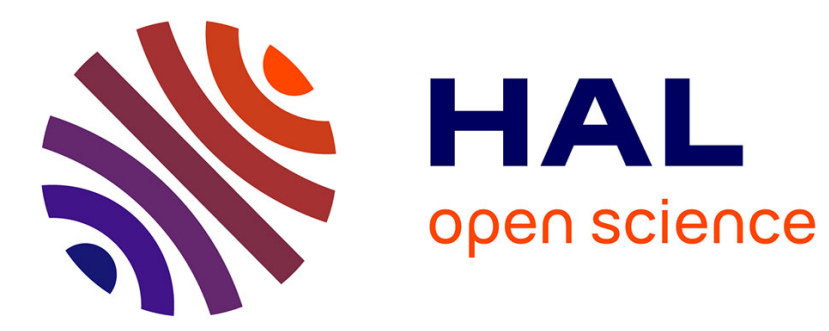

\title{
Computational prediction of the lifetime of self-healing CMC structures
}

Martin Genet, Lionel Marcin, Emmanuel Baranger, Christophe Cluzel, Pierre Ladevèze, Anne Mouret

\section{- To cite this version:}

Martin Genet, Lionel Marcin, Emmanuel Baranger, Christophe Cluzel, Pierre Ladevèze, et al.. Computational prediction of the lifetime of self-healing CMC structures. Composites Part A: Applied Science and Manufacturing, 2011, pp.294-303. 10.1016/j.compositesa.2011.11.004 . hal-00749632

\section{HAL Id: hal-00749632 \\ https://hal.science/hal-00749632}

Submitted on 7 Nov 2012

HAL is a multi-disciplinary open access archive for the deposit and dissemination of scientific research documents, whether they are published or not. The documents may come from teaching and research institutions in France or abroad, or from public or private research centers.
L'archive ouverte pluridisciplinaire HAL, est destinée au dépôt et à la diffusion de documents scientifiques de niveau recherche, publiés ou non, émanant des établissements d'enseignement et de recherche français ou étrangers, des laboratoires publics ou privés. 


\title{
Computational prediction of the lifetime of self-healing CMC structures
}

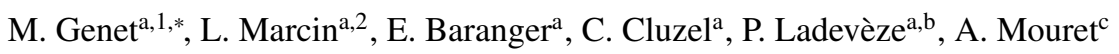 \\ ${ }^{a}$ LMT-Cachan, ENS-Cachan/CNRS UMR8535/Paris VI University/UniverSud Paris PRES, 61 avenue du Président Wilson, 94235 Cachan Cedex, France \\ ${ }^{b}$ EADS Foundation Chair "Advanced Computational Structural Mechanics" \\ ${ }^{c}$ SAFRAN-Snecma Propulsion Solide, Les cinq chemins, 33187 Le Haillan Cedex, France
}

\begin{abstract}
Self-healing Ceramic Matrix Composites (CMCs) are good candidates for structural applications at high temperatures in oxidizing environments. These materials generate complex couplings between the thermal and mechanical fields. A multiphysics macroscopic model of both the mechanical behavior and the lifetime of CMC structures was proposed previously and was validated on the material's level. Here, its effectiveness in dealing with structural calculations with heterogeneous fields is analyzed and a non-local fracture criterion is proposed for high-gradient cases. All the simulations were carried out using Abaqus/Standard. The main interest of the model is its ability to predict the evolution of each of the material's mechanisms throughout the structure until final fracture. Another advantage is the ability to predict the fracture zone and the influence of indentations on the lifetime of the structure (damage tolerance analysis), both of which are very important for industrial developments.
\end{abstract}

Keywords:

A. Ceramic matrix composites, B. Environmental degradation, B. Mechanical properties, C. Finite Element Analysis (FEA)

\section{Contents}

\section{Introduction}

\section{The modeling of mechanical damage}

2.1 The nonlinear behavior model

2.1 .1 State law ............. 3

2.1.2 Damage evolution laws ........ 3

2.1.3 Residual strain . . . . . . . . . . . . 3

2.1.4 Nonlinear response ......... 4

2.2 Fracture criterion . . . . . . . . . . . . 4

2.3 Crack opening indicator . . . . . . . . 4

3 Modeling of environmental damage and healing

3.1 Matrix healing . . . . . . . . . . .

3.2 Fiber degradation . . . . . . . . . . .

4 Illustration and validation of the strategy

4.1 Predictions of the damage fields . . . . . . .

4.2 Lifetime predictions . . . . . . . . . . . .

4.2.1 First case: homogeneous temperature field . . . . . . . . . . . . . 7

4.2.2 Second case: temperature gradient . . . 8

\section{Application to damage tolerance analysis}

5.1 Predictions of the damage fields . . . . . . .

5.2 Lifetime predictions . . . . . . . . . . .

\footnotetext{
*Corresponding author. E-mail address: mgenet@1mt.ens-cachan.fr

${ }^{1}$ Current address: Lawrence Berkeley National Laboratory, Materials Department 62-0237, 1 Cyclotron Road, Berkeley, CA 94720, USA

${ }^{2}$ Current address: Snecma Villaroche, Rond Point René Ravaud, 77550 Moissy-Cramayel, France
}

6 Conclusion

\section{Introduction}

Ceramic Matrix Composites (CMCs) have very good thermomechanical properties and, thanks to self-healing matrices, can be made to resist oxidation. Therefore, they are potential candidates for high-temperature applications, such as engine components in the aeronautical industry [Naslain, 2004; Bourgeon, 2010].

From a mechanical standpoint, the key phenomenon is the deflection of the matrix cracks in the fiber-matrix interphase [Aveston et al., 1971; Marshall and Evans, 1985; Marshall et al., 1985]: this mechanical fuse protects the fibers from the cracks and enables the development of multiple cracks in the matrix, giving the composite some level of ductility, even though all of its constituents are brittle. The matrix cracking scenario has already been established for woven CMCs [Guillaumat and Lamon, 1996; Lamon, 2001]. Since the matrix between the yarns is stiffer, but more brittle, and has larger pores than the yarns themselves, it begins to crack first. The corresponding cracks are oriented by the loading and are orthogonal to the applied stress. Then, when this crack network nearly reaches saturation, the matrix in the yarns also begins to crack. The corresponding cracks are oriented by the fibers: they are orthogonal to the fibers in longitudinal yarns, and parallel to the fibers in transverse yarns. In summary, there are three types of cracks in the damaged material: (i) inter-yarn cracks, (ii) intra-yarn longitudinal cracks and (iii) intra-yarn transverse cracks.

However, the matrix crack network (especially the intra-yarn transverse cracks) is a preferential path for the diffusion of air 
(actually oxygen, water, etc) within the material toward the fibers, which are prone to subcritical cracking in an oxidizing or corrosive atmosphere [Gauthier and Lamon, 2009; Gauthier et al., 2009; Ladevèze and Genet, 2010]. Therefore, there have been attempts to introduce an environmental protection of the fibers within the composite (a chemical fuse capable of breaking the oxygen circuit), such as a self-healing multilayered matrix [Lamouroux et al., 1999; Naslain et al., 2001], which would drastically increase the material's lifetime [Cluzel et al., 2009].

In order to predict the mechanical behavior and the lifetime of such a complex system, a multiphysics model was already proposed in [Ladevèze et al., 2001; Cluzel et al., 2007; Baranger et al., 2007; Cluzel et al., 2009]. The key element of this lifetime prediction tool is the mechanical model of the matrix cracking process, which was introduced for CMCs in [Ladevèze and Letombe, 2000; Ladevèze, 2002] and belongs to the framework of anisotropic and unilateral damage theory [Ladevèze, 1983, 2002]. The second main ingredient is the physicochemical model of the matrix healing and fiber degradation processes which was introduced in [Ladevèze et al., 2001; Cluzel et al., 2007, 2009]. The principle of the global lifetime model is the following. In the first stage, the mechanical model provides a homogenized description of the various matrix crack networks on the macroscopic scale. It is important to note that even though the model is macroscopic it treats each crack network separately in the description of the damage. Therefore, one can define a crack opening indicator specifically for the intra-yarn transverse cracks. These cracks constitute the input data of the second stage, in which the physicochemical model provides a description of $(i)$ the development of the oxide tip within a single reference crack, (ii) the diffusion of oxygen and water within this oxide and (iii) the degradation of the material's strength through fiber oxidation/corrosion. Let us point out that, more recently, slightly different healing strategies have been tested on $\mathrm{C} / \mathrm{SiC}$ composites (e.g. in [Liu et al., 2008]) and characterized (e.g. in [Tong et al., 2008; Liu et al., 2011; Zhang et al., 2011]). In addition, several studies of the cyclic fatigue (both thermal and mechanical) of $\mathrm{C} / \mathrm{SiC}$ composites have been carried out [Mei et al., 2006; Mei and Cheng, 2011].

The aim of this paper is to extend the analysis presented in [Cluzel et al., 2009] by using recent developments which enable one to come even closer to industrial needs. Indeed, the whole lifetime prediction scheme (Figure 1) can now be applied to structural parts subjected to heterogeneous stress and/or temperature fields, possibly with high gradients.

First, we briefly review the mechanical foundation, which was already published in [Ladevèze and Letombe, 2000; Ladevèze, 2002], in order to make it easier for the reader to understand the particular case of static loading. (For fatigue loading, one may refer to [Baranger et al., 2007; Cluzel et al., 2009].) Moreover, in order to be able to take into account structures with high stress and/or temperature gradients, we introduce a nonlocal fracture criterion and describe it in detail. In addition, again for the reader's understanding, we also review

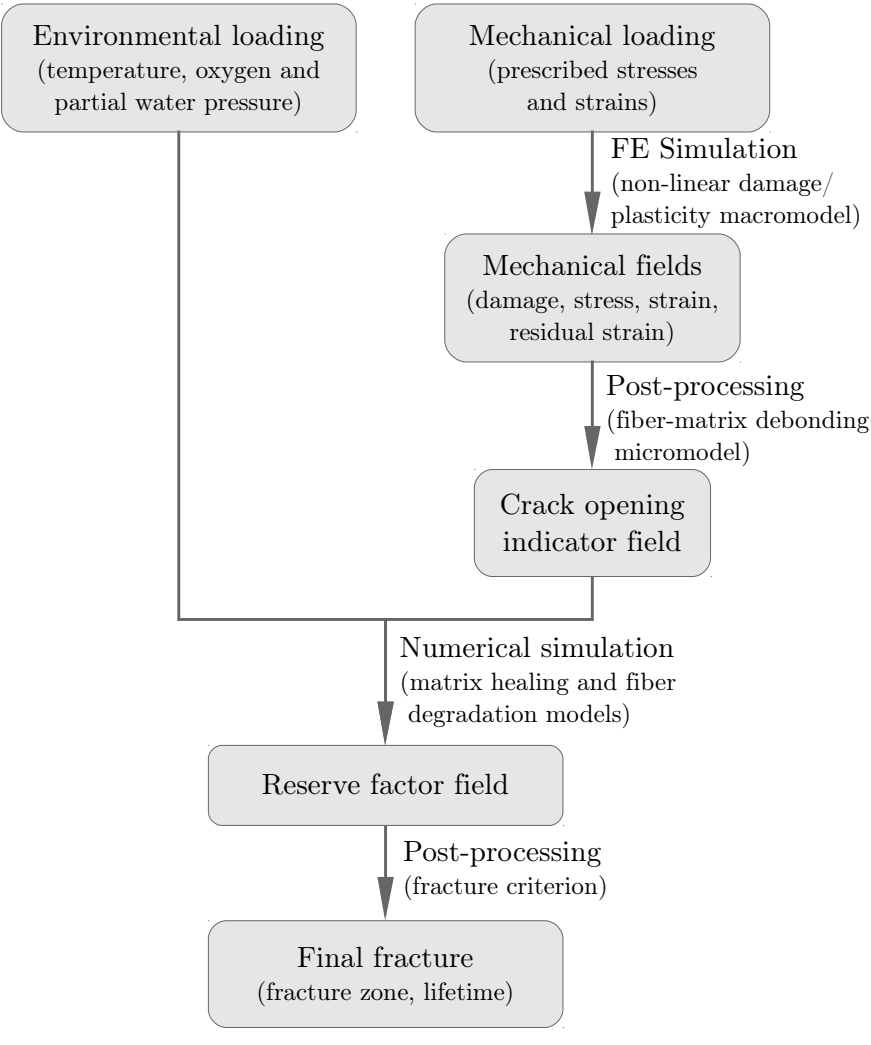

Figure 1: The strategy for the lifetime prediction of self-healing CMC structures

the main lines of physicochemical models. (Further details can be found in [Cluzel et al., 2007, 2009].)

Then, we apply the lifetime model to several structural tests. The first test concerns a dog bone specimen subjected to tension. The combined action of the mechanical and thermal fields is analyzed in both hot and cold grip experiments (i.e. homogeneous and heterogeneous temperature fields), and elements of validation are presented. The fact that the model is capable of predicting the location of the specimen's fracture zone is found to be very useful for the design of lifetime experiments on structures. The second structural test concerns a plate with a circular opening subjected to tension (open-hole test). This test enables us to assess the effectiveness of the strategy in the case of multiaxial stress fields with high stress gradients. Then, having established a certain degree of confidence in the strategy, we begin to outline a damage tolerance analysis through the prediction of a specimen's residual properties and lifetime after impact. This answers one of the main industrial concerns regarding the development of new composite structures [Cox and Yang, 2006; Bourgeon, 2010].

\section{The modeling of mechanical damage}

\subsection{The nonlinear behavior model}

The mechanical model takes into account the crack networks and the associated fiber-matrix debonding through damage and inelastic strains. While the inelastic part is relatively 
classical, the damage part is based on anisotropic and unilateral damage theory, a powerful damage approach introduced in [Ladevèze, 1983, 2002] and previously applied to C/C [Aubard et al., 1998] and SiC/SiC [Gasser et al., 1996] composites and to concrete [Desmorat et al., 2007]. The first version of the theory used second-order tensors to represent mechanical damage [Ladevèze, 1983]. It was superseded by a second version which uses fourth-order tensors [Ladevèze, 2002]. The same choice was also made by [Lesne and Saanouni, 1993; Voyiadjis and Kattan, 1993]. The unilateral character of damage (which under compression loading is passive) is taken into account without resorting to a discontinuous state law. This property is also present, in a different form, in [Pensée et al., 2002; Chaboche and Maire, 2002; Marcin et al., 2010]. Finally, the approach has the particularity of treating each damage mechanism (inter-yarn cracking, intra-yarn longitudinal cracking and intra-yarn transversal cracking) separately. The main constitutive equations, as implemented in the finite element industrial code Abaqus/Standard, will now be reviewed.

\subsubsection{State law}

The potential of elastic energy density is expressed in terms of the stress tensor $\sigma$ and divided into three parts: (i) a first part which is active only in traction and which takes into account the damage state, (ii) a second part which is active only in compression and which is independent of the damage state and (iii) a third part which is always active and also involves some damage. Thus, this potential can be expressed as:

$$
e_{d}=\frac{1}{2} \operatorname{Tr}\left[\mathbb{C} \sigma^{+} \sigma^{+}\right]+\frac{1}{2} \operatorname{Tr}\left[\mathbb{C}_{0} \sigma^{-} \sigma^{-}\right]+\frac{1}{2} \operatorname{Tr}[\mathbb{Z} \sigma \sigma]
$$

where $\mathbb{C}_{0}, \mathbb{C}$ and $\mathbb{Z}$ are three fourth-order tensors representing respectively the initial compliance, the damaged compliance and a compliance operator associated with shear damage. In addition, a special decomposition of the stress tensor into a positive part and a negative part is used in order to ensure the continuity of the state law [Ladevèze, 2002]:

$$
\left\{\begin{array}{l}
\sigma^{+}=\mathbb{C}^{-1 / 2}:<\mathbb{C}^{1 / 2}: \sigma>_{+} \\
\sigma^{-}=\mathbb{C}_{0}^{-1 / 2}:<\mathbb{C}_{0}^{1 / 2}: \sigma>_{-}
\end{array}\right.
$$

where $<>_{+/-}$denote the classical positive and negative parts of the quantities being considered. It is important to remember that both the positive part and the negative part must be taken in that special sense (and not in the classical sense) in order to avoid having to deal with a discontinuous state law.

Thus, the state law becomes:

$$
\boldsymbol{\epsilon}^{e}=\frac{\partial e_{d}}{\partial \boldsymbol{\sigma}}=\mathbb{C} \sigma^{+}+\mathbb{C}_{0} \sigma^{-}+\mathbb{Z} \boldsymbol{\sigma}
$$

where $\boldsymbol{\epsilon}^{e}$ is the elastic strain tensor.

The energy release rates associated with the variations of internal variables $\mathbb{C}$ and $\mathbb{Z}$ (i.e. the thermodynamical forces) are:

$$
\left\{\begin{array}{l}
\mathbb{Y}=\frac{\partial e_{d}}{\partial \mathbb{C}}=\frac{1}{2} \sigma^{+} \otimes \sigma^{+} \\
\mathbb{Y}^{\prime}=\frac{\partial e_{d}}{\partial \mathbb{Z}}=\frac{1}{2} \sigma \otimes \sigma
\end{array}\right.
$$

Finally, an additional thermodynamic force, which is required to drive shear damage correctly, is defined as:

$$
\begin{aligned}
& \mathbb{Y}^{\prime \prime}=\frac{1}{2}\left(i_{\pi / 2} \sigma^{+}\right)_{\mathrm{sym}} \otimes\left(i_{\pi / 2} \sigma^{+}\right)_{\mathrm{sym}} \\
& \text { with } i_{\pi / 2}=\left[\begin{array}{cc}
0 & -1 \\
1 & 0
\end{array}\right]
\end{aligned}
$$

\subsubsection{Damage evolution laws}

Each degradation mechanism is associated with a damage evolution law which affects part or all of tensors $\mathbb{C}$ and $\mathbb{Z}$ :

$$
\left\{\begin{array}{l}
\dot{\mathbb{C}}=\dot{\mathbb{C}}_{m}+\dot{\mathbb{C}}_{f_{1}}+\dot{\mathbb{C}}_{f_{2}} \\
\dot{\mathbb{Z}}=\dot{\mathbb{Z}}_{m}+\dot{\mathbb{Z}}_{f_{1}}+\dot{\mathbb{Z}}_{f_{2}}
\end{array}\right.
$$

where $\dot{\mathbb{C}}_{m}$ and $\dot{\mathbb{Z}}_{m}$ represent inter-yarn matrix cracking, $\dot{\mathbb{C}}_{f_{1}}$ and $\dot{\mathbb{Z}}_{f_{1}}$ represent intra-yarn matrix cracking of the longitudinal tows, and $\dot{\mathbb{C}}_{f_{2}}$ and $\dot{\mathbb{Z}}_{f_{2}}$ represent intra-yarn matrix cracking of the transverse tows.

For instance, regarding inter-yarn matrix cracking, we consider the following effective thermodynamic force and its maximum over time:

$$
\left\{\begin{array}{l}
z_{m}=\left(a \operatorname{Tr}[\widehat{\mathbb{Y}}]^{n+1}+(1-a) \operatorname{Tr}\left[\widehat{\mathbb{Y}}^{n+1}\right]\right)^{1 / n+1} \\
\bar{z}_{m}(t)=\sup _{\tau \leq t} z_{m}(\tau)
\end{array}\right.
$$

and the definition of the evolution law becomes:

$$
\left\{\begin{array}{l}
\dot{\widehat{\mathbb{C}}}_{m}=\dot{\alpha}_{m} \frac{a(\operatorname{Tr}[\widehat{\mathbb{Y}}])^{n} \mathbb{I}+(1-a) \widehat{\mathbb{Y}}^{n}}{\bar{z}_{m}^{n}} \\
\dot{\mathbb{Z}}_{m}=\dot{\alpha}_{m} \frac{b \widehat{\mathbb{Y}}^{\prime \prime}}{\bar{z}_{m}^{n}}
\end{array}\right.
$$

where $\alpha_{m}$ is a function of $\bar{z}_{m}$ which needs to be calibrated experimentally, and $a, b, n$ are parameters of the model defining damage anisotropy (usually chosen as $a=0.1, b=2$ and $n=2)$.

The other damage evolution laws have similar expressions [Ladevèze, 2002].

\subsubsection{Residual strain}

The total strain rate is divided into elastic and residual strain rates:

$$
\dot{\boldsymbol{\epsilon}}^{t}=\dot{\boldsymbol{\epsilon}}^{e}+\dot{\boldsymbol{\epsilon}}^{r}
$$

The evolution of the residual strain is modeled using two uncoupled classical formulations of associated plasticity with isotropic hardening (one for in each tow direction):

$$
\dot{\boldsymbol{\epsilon}}^{r}=\dot{\boldsymbol{\epsilon}}^{r_{1}}+\dot{\boldsymbol{\epsilon}}^{r_{2}}
$$

For instance, regarding the longitudinal tow, we consider the following effective and equivalent stresses:

$$
\begin{aligned}
& \left\{\begin{array}{l}
\overline{\boldsymbol{\sigma}}_{1}=\mathbb{P}_{1} \mathbb{C}_{0}^{-1} \boldsymbol{\sigma}^{+} \\
\bar{\sigma}_{1}^{\mathrm{eq}}=\sqrt{\operatorname{Tr}\left[\overline{\boldsymbol{\sigma}}_{1}^{2}\right]}
\end{array}\right. \\
& \text { with } \widehat{\mathbb{P}}_{1}=\left[\begin{array}{lll}
1 & 0 & 0 \\
0 & 0 & 0 \\
0 & 0 & \beta
\end{array}\right]
\end{aligned}
$$


where $\beta$ is a model parameter defining the influence of shear on inelasticity (usually chosen as $\beta=2$ ). The yield surface is defined simply by the characteristic function:

$$
f=\sigma_{1}^{\mathrm{eq}}-R\left(r_{1}\right)-R_{0}=0
$$

where $r_{1}$ is the cumulative residual strain and $R$ is the classical hardening function, which must be calibrated experimentally. Thus, the associated plasticity principle defines the following evolution law:

$$
\left\{\begin{array}{l}
\dot{\overline{\boldsymbol{\epsilon}}}^{r_{1}}=\dot{\lambda} \frac{\partial f}{\partial \boldsymbol{\sigma}}=\dot{\lambda} \frac{\overline{\boldsymbol{\sigma}}_{1}}{\sqrt{\operatorname{Tr}\left[\overline{\boldsymbol{\sigma}}_{1}^{2}\right]}} \\
\dot{r}_{1}=-\dot{\lambda} \frac{\partial f}{\partial R}=\dot{\lambda}
\end{array}\right.
$$

where $\overline{\boldsymbol{\epsilon}}^{r_{1}}$ is the effective residual strain rate and $\lambda$ is the residual multiplier, which can be calculated through the consistency principle. Finally, in order to keep the dissipation constant, the actual residual strain rate is given by:

$$
\dot{\boldsymbol{\epsilon}}^{r_{1}}=\mathbb{P}^{1} \mathbb{C}_{0}^{-1} \dot{\overline{\boldsymbol{\epsilon}}}^{r_{1}}
$$

The formulation for the transversal tow is similar [Letombe, 2005; Baranger et al., 2007].

\subsubsection{Nonlinear response}

Very good agreement of this model with available experimental data has been reported [Baranger et al., 2007, 2008]. Figure 2 shows the model's response to an incremental tension/compression longitudinal loading on SAFRAN-Snecma Propulsion Solide's CERASEP®A410 material as identified in [Letombe, 2005; Baranger et al., 2007]. One can clearly distinguish (i) the stiffness reduction due to cracking, (ii) the stiffness recovery in compression due to the closure of the cracks and (iii) the residual strain due to fiber-matrix debonding.

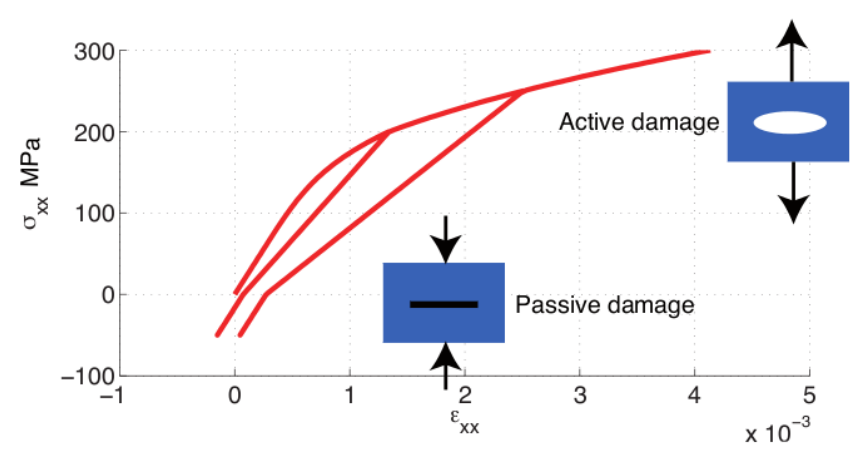

Figure 2: The response of the mechanical model to an incremental tension/compression test in the longitudinal direction

\subsection{Fracture criterion}

The characterization of a structure's final fracture and the prediction of its lifetime require an additional tool. Indeed, while the model described previously is capable of predicting the microscopic damage which develops within the material, it is not directly suitable for the prediction of damage localization and macroscopic fracture. Therefore, since it is well-known that local failure criteria cannot predict the final fracture of materials properly [Whitney and Nuismer, 1974], we use a nonlocal fracture criterion. This approach is based on the work of [Nuismer and Whitney, 1975] and it has already been shown to be effective for the analysis of polymers [Hochard et al., 2007; Miot et al., 2010] as well as for the fracture analysis of ceramic matrix composites [Flores et al., 2010].

The criterion is very simple both in concept and in practice (see Figure 3). It consists in averaging, for each tow direction, the stress field over an area $\Omega$ defined by a length $l_{0}$ considered to be an intrinsic parameter of the material. (In practice, we use the size of a weave pattern, i.e. $2 \mathrm{~mm}$.) For instance, for the longitudinal tow, the fracture criterion is:

$$
\begin{gathered}
\exists \underline{x} / \tilde{\sigma}_{1}(\underline{x}) \geq \sigma_{1}^{R}(\underline{x}) \\
\text { with } \quad \tilde{\sigma}_{1}(\underline{x})=\frac{1}{|\Omega|} \int_{\Omega} \sigma_{11}^{+}\left(\underline{x}^{\prime}\right) \underline{d x^{\prime}} \quad \forall \underline{x}
\end{gathered}
$$

The formulation for the transversal tow is similar.

This fracture criterion can be rewritten differently based on the normalized residual strength (or strength reserve factor) field [Department of Defence, 2002]. This quantity provides the best illustration of the relation between the stress field (imposed by the boundary conditions) and the strength field (which evolves over time because of environmental damage) during the fracture process, and is defined by:

$$
\tilde{\sigma}_{1}^{R}(\underline{x})=\frac{\sigma_{1}^{R}(\underline{x})}{\tilde{\sigma}_{1}(\underline{x})} \quad \forall \underline{x}
$$

Then, the fracture criterion becomes:

$$
\exists \underline{x} / \tilde{\sigma}_{1}^{R}(\underline{x}) \leq 1
$$

$$
\begin{aligned}
& \text { Considered Gauss point } \\
& \text { Neighboring Gauss points }
\end{aligned}
$$

Figure 3: Illustration of the nonlocal failure criterion

\subsection{Crack opening indicator}

Since the damage model treats the different crack networks separately, it is relatively easy to develop a physical indicator of intra-yarn matrix crack opening starting from macroscopic 
damage variables and using a micromodel [Cluzel et al., 2007, 2009] based on a proposal by [Aveston et al., 1971; Rouby and Reynaud, 1993; Evans et al., 1995]. For instance, in the longitudinal direction, one has:

$$
h_{1}=\frac{1}{d_{f_{1}}}\left(K_{1} \epsilon_{11}^{r_{1}}+K_{2} \Delta C_{11}^{f_{1}} \tilde{\sigma}_{1}\right)
$$

where $h_{1}$ is the average opening of a crack, $d_{f_{1}}$ is the crack density, and $K_{1}, K_{2}$ are parameters of the model (see [Cluzel et al., 2007, 2009] for further details on the calibration of these parameters from the micromodel). Moreover, $\epsilon_{11}^{r_{1}}$ is the residual strain in the longitudinal direction induced by the cracking of the longitudinal tow (see Equation (14)), $\Delta C_{11}^{f_{1}}$ is the variation in compliance in the longitudinal direction induced by the cracking of the longitudinal tow (see Equation (6) and refer to [Ladevèze and Letombe, 2000] for further details), and $\tilde{\sigma}_{1}$ is the nonlocal stress in the longitudinal direction (see Equation (15)). The expression in the transversal direction is similar. Finally, this crack opening indicator creates the link between the mechanical macromodel and the physicochemical micro/mesomodel.

\section{Modeling of environmental damage and healing}

The physicochemical part of the model involves two mechanisms: (i) matrix healing, which is described in the classical diffusion-reaction framework on the fiber's scale, and (ii) fiber degradation, which is described in a more phenomenological way on the scale of the fiber bundle.

\subsection{Matrix healing}

The self-healing mechanism consists in filling the cracks with a viscous glass, produced by the oxidation of some matrix layers, in order to reduce the diffusion of oxygen from the composite's pores to the fibers [Naslain, 2004; Quemard et al., 2007]. Both the growth of this oxide plug and the oxygen diffusion within it can be modeled by the simple diffusion-reaction equation [Quemard et al., 2007; Cluzel et al., 2007, 2009]. The geometry being considered is that of a single reference crack [Cluzel et al., 2007, 2009], whose geometric parameters are obtained from measurements of the material and in which the opening of the crack is determined by the indicator defined previously. The associated problem is solved using a robust numerical algorithm which takes into account the change in geometry of the oxide plug both during its growth and during its decrease [Cluzel et al., 2007, 2009]. The output of the model is the evolution of the oxygen concentration around the fiber over time and as a function of the damage state, the stress field, the temperature, etc. One can observe that the presence of water vapor accelerates the plug's growth, which is also taken into account in the model thanks to experimental data provided by [Rebillat et al., 2004; Garitte et al., 2006].

\subsection{Fiber degradation}

It was proven by [Gauthier and Lamon, 2009; Gauthier et al., 2009; Laforêt and Lamon, 2008] that the delayed fracture of
$\mathrm{SiC}$ fibers under given mechanical and environmental conditions is due to the subcritical propagation of their surface defects. The modeling approach proposed by these authors is based on a Paris-like law for the subcritical propagation of defects, leading to a fatigue-like law for the fibers' lifetime. However, while these predictions are in good agreement with experimental data under constant environmental conditions, the model is not directly applicable if the concentration of oxidative or corrosive agents around the fibers varies. Another approach which takes into account the fiber's environment and is, therefore, directly applicable to varying conditions was recently proposed in [Ladevèze and Genet, 2010], but has not yet been applied to fiber bundles. Therefore, we use the following modified fatigue law [Cluzel et al., 2007, 2009] as the strength evolution law for the longitudinal fiber bundles:

$$
\begin{gathered}
\theta_{1}(t) \sigma_{1}^{R}(t)^{n}=A \\
\text { with } \quad \theta_{1}(t)=\int_{0}^{t} c_{O_{2}}^{1}(\tau) \exp \left(-\frac{E_{A}}{R T}\right) d \tau
\end{gathered}
$$

where $c_{\mathrm{O}_{2}}^{1}$ is the evolving oxygen concentration around the longitudinal fibers given by the matrix healing model and $A, E_{A}$ are model parameters which must be identified experimentally. The expression in the transversal direction is similar.

\section{Illustration and validation of the strategy}

The mechanical model with anisotropic and unilateral damage and with residual strain was implemented in Abaqus/Standard as a $\mathrm{C}++$ UMat. Indeed, while there are other methods to solve nonlinear problems [Ladevèze, 1999; Passieux et al., 2010] which have been used for the simulation of composites [Kerfriden et al., 2009], Newton-Raphson is the most popular method for dealing with material nonlinearities in science and engineering, and Abaqus is one of the most widespread FE codes, especially in industry. The UMat is based on the software development platform of [Leclerc, 2010]. Essentially, the local loop consists of nested fixedpoint iterations and Newton-Raphson iterations, the former to calculate the damage state and the latter to invert the state law (which is nonlinear, even when all the state variables are fixed, see Equation (3)). Moreover, Aitken's relaxation and the BFGS pseudo-tangent operator are used in the fixed-point and Newton-Raphson algorithms respectively in order to improve the convergence rate. The details of the implementation, including analyses of the efficiency and robustness, will be the subjects of a forthcoming paper[Genet et al., 2011].

Concerning the lifetime model, this part was implemented in Matlab. Essentially, the geometry of the modeled crack partially filled with the oxide plug is discretized using unidirectional linear elements. The diffusion equations are solved analytically while the reaction process is solved using a RungeKutta/Fehlberg method in order to control the quality of the solution.

Finally, the interface between the two codes and the averaging calculations required for the fracture criterion are provided by Python scripts. 
Thanks to these numerical developments, the predictive capabilities of the whole strategy can now be illustrated by structural cases. The first example is a dog bone specimen made of SAFRAN-Snecma Propulsion Solide's CERASEP®A410 self-healing CMC (Figure 4). The FE mesh was generated using GMSH [Geuzaine and Remacle, 2009]. The specimen was subjected to a static fatigue loading at high temperature: all the loading conditions, i.e. the applied stress and temperature and the other environmental conditions (20kPa partial oxygen pressure; $1.8 \mathrm{kPa}$ partial water pressure) remained constant over time.

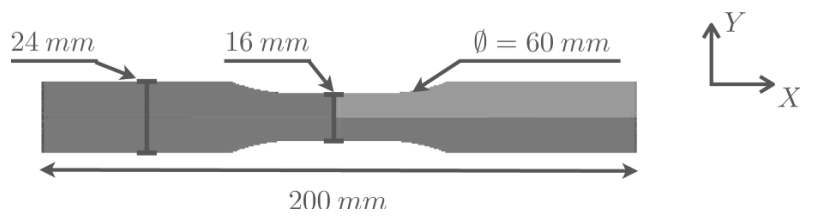

Figure 4: The geometry of the dog bone specimen subjected to tension in the $\mathrm{x}$-direction

We used an identification of the model for this material provided by [Baranger et al., 2007, 2008; Cluzel et al., 2007]. While some parameters (e.g. the reaction/diffusion coefficients) can be found in the literature, most were identified by fitting the mechanical response of macroscopic specimens (e.g. initial behavior, damage evolution laws) or by analyzing the morphology of the material on the fiber's scale (e.g. the characteristic dimensions of the matrix layers). Still, a few parameters (e.g. the anisotropy of the cracks) remained unidentified because of the lack of experimental data and had to be chosen arbitrarily [Letombe, 2005].

We will present first the damage induced by the mechanical loading (i.e. the stiffness reduction), followed by the damage induced by the environment (i.e. the strength reduction).

\subsection{Predictions of the damage fields}

As mentioned previously, the key property of the model is that it distinguishes among the contributions associated with each crack network, which, thus, can be analyzed separately. For instance, for a 50MPa applied load, inter-yarn damage alone is in effect, whereas for a 250MPa applied load (Figure 5(a)), both inter-yarn matrix damage and intra-yarn matrix damage are in effect (Figures 5(b) and 5(c)): intra-yarn damage takes over after inter-yarn damage has reached saturation. Let us point out that this is the first time damage fields from a model based on the second version of the anisotropic and unilateral damage theory [Ladevèze, 2002] are being presented.

The mechanical part also provides an intra-yarn transverse crack opening indicator field, which is the key input to the physicochemical model of strength reduction through oxidation.

\subsection{Lifetime predictions}

Now, let us illustrate the capability of our strategy to simulate the complex competition between mechanical loading and environmental loading through the analysis of two related test

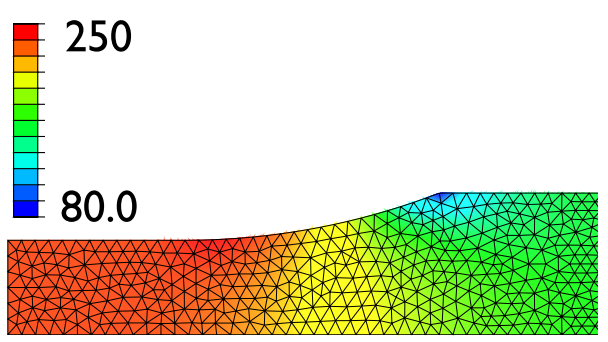

(a) Longitudinal stress $\sigma_{11}(\mathrm{MPa})$

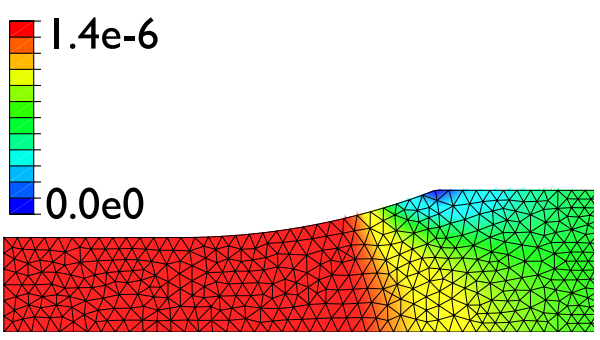

(b) Inter-yarn matrix damage $\alpha_{m}$ ( )

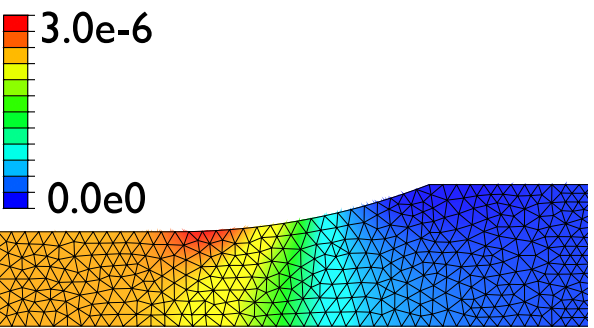

(c) Intra-yarn matrix longitudinal damage $\alpha_{f_{1}}$ ( )

Figure 5: The dog bone specimen subjected to a 250MPa traction: (a) longitudinal stress, (b) inter-yarn matrix damage, (c) intra-yarn matrix damage 
cases: a hot grip experiment (i.e. with a homogeneous temperature field) and a cold grip experiment (i.e. with a temperature gradient over the specimen).

\subsubsection{First case: homogeneous temperature field}

The use of hot-grip testing machines greatly simplifies the study of the lifetime of self-healing CMCs because these machines allow the analysis of the influence of the stress and temperature fields on the lifetime to be fully uncoupled. Therefore, let us first consider the use of our model to analyze hot-grip experiments.

Figure 6 shows the strength degradation in the specimen after 278 hours under $200 \mathrm{MPa}$ loading at two uniform temperatures $\left(500^{\circ} \mathrm{C}\right.$ and $\left.700^{\circ} \mathrm{C}\right)$. In this case of a homogeneous temperature field, the interaction with the damage field (which is nearly homogeneous, too) is the following: the strength decreases mainly in the middle of the specimen, where the stress is higher. For instance, from the initial value of $340 \mathrm{MPa}$, the strength reduced to about $120 \mathrm{MPa}$ at $500^{\circ} \mathrm{C}$ (Figure 6(a)), and to only about $210 \mathrm{MPa}$ at $700^{\circ} \mathrm{C}$ (Figure 6(b)). Figure 7 shows the same type of result, this time for the strength reserve factor field. This shows clearly that at $500^{\circ} \mathrm{C}$ the specimen breaks in the zone of interest whereas at $700^{\circ} \mathrm{C}$ it does not break at all.

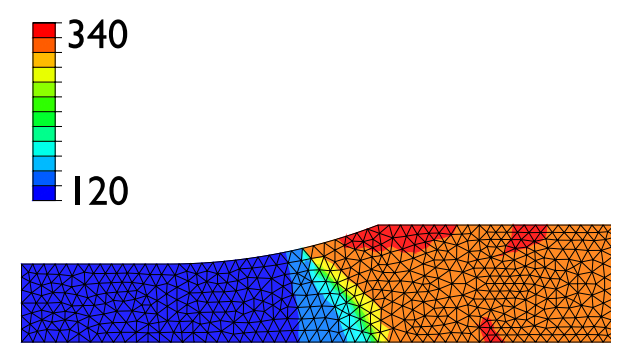

(a) $\mathrm{T}=500^{\circ} \mathrm{C}$

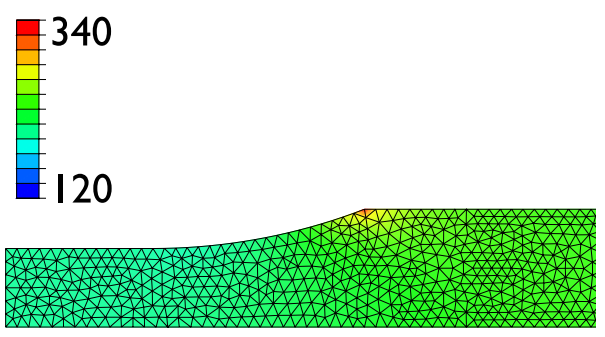

(b) $\mathrm{T}=700^{\circ} \mathrm{C}$

Figure 6: Without temperature gradient: the residual strength at two temperatures (200MPa loading for 278 hours)

This shows that the model is capable of illustrating and quantifying classical types of behavior: ( $i$ ) an increase in the applied stress decreases the lifetime of the specimen drastically (see Figure 8, which indicates a very good match with experimental data); (ii) a modification in the applied temperature enables one to define the domain of applicability of the healing process ([Cluzel et al., 2007, 2009]). Let us note that the wide scatter in the lifetime data of Figure 8 was evidenced only in a recent study [De Melo-Loseille and Lamon, 2009] and will be analyzed within our modeling framework in a forthcoming paper.

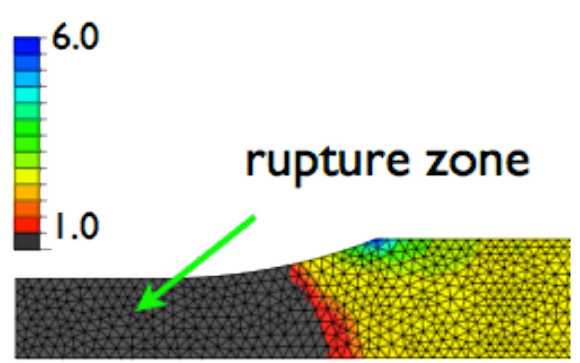

(a) $\mathrm{T}=500^{\circ} \mathrm{C}$

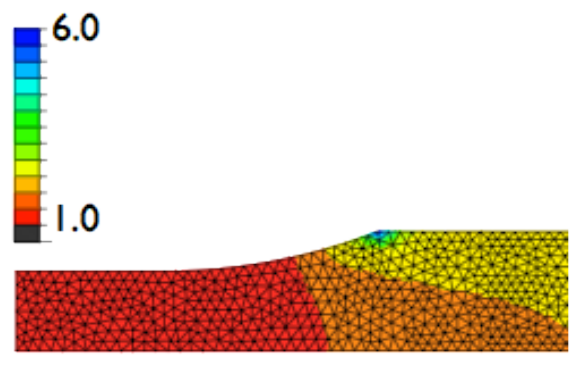

(b) $\mathrm{T}=700^{\circ} \mathrm{C}$

Figure 7: Without temperature gradient: the strength reserve factor at two temperatures (200MPa loading for 278 hours)

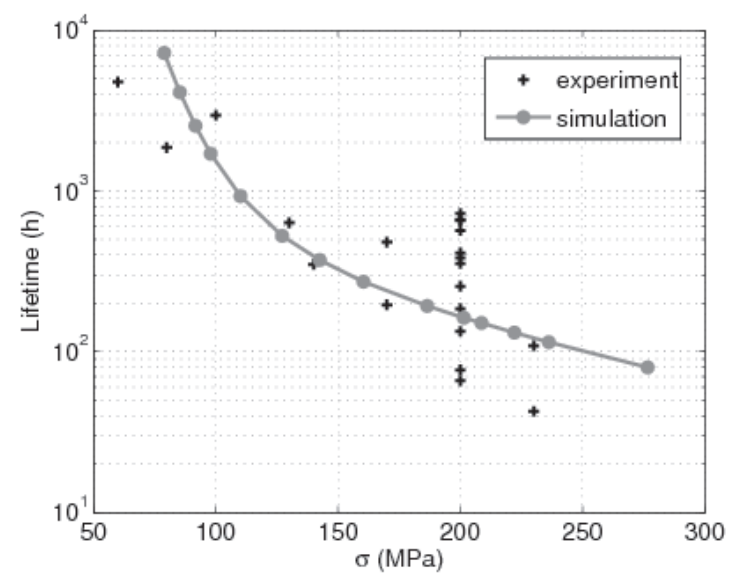

Figure 8: Comparison of the lifetime predictions between model and experiment: stress dependence at $500^{\circ} \mathrm{C}$ (experimental data from [Penas, 2002; Moevus, 2007; De Melo-Loseille and Lamon, 2009]) 


\subsubsection{Second case: temperature gradient}

Hot-grip testing machines are uncommon and most experiments are carried out using cold-grip machines. This makes the analysis complicated because neither the stress field nor the temperature field, both of which have a significant impact on the lifetime, is uniform [De Melo-Loseille and Lamon, 2009; Momon et al., 2010]. This led us to apply our model to the analysis of cold-grip experiments in order to illustrate how it can help improve their design and understanding. The temperature field considered was obtained by [Moevus, 2007] and is shown in Figure 9.
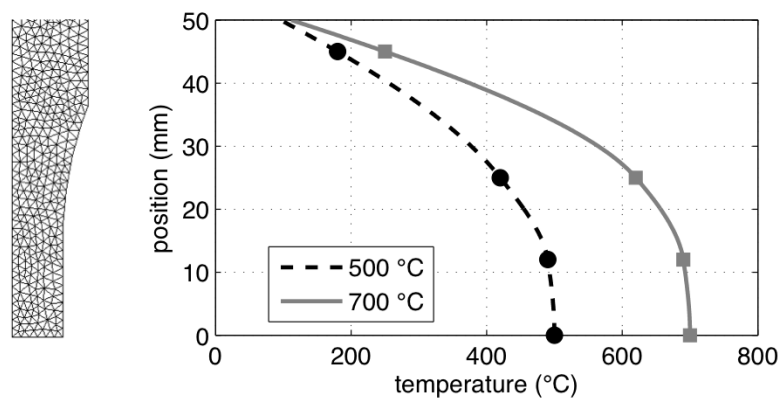

Figure 9: The temperature gradient in the dog bone specimen in a cold-grip testing machine at two temperatures [De Melo-Loseille and Lamon, 2009]

Figures 10 and 11 show the residual strength and the strength reserve factor in the specimen after 278 hours under $200 \mathrm{MPa}$ loading at two non-uniform temperatures $\left(500^{\circ} \mathrm{C} \max\right.$ and $700^{\circ} \mathrm{C}$ max). For a $500^{\circ} \mathrm{C}$ prescribed temperature in the center of the specimen, the predicted strengths (Figures 10(a) and 11(a)) are very close to those with a uniform temperature (Figures 6(a) and 7(a)). Indeed, in this temperature range the healing process has almost no influence. Conversely, for a $700^{\circ} \mathrm{C}$ prescribed temperature in the center of the specimen, the predicted strengths (Figures 10(b) and 11(b)) are markedly different from those with a uniform temperature (Figures 6(b) and 7(b)): the strength degradation patterns can be very complex. Indeed, due to the fact that the effectiveness of the oxide tip varies significantly, and especially non-monotonically, as a function of the temperature [Cluzel et al., 2009], the strength degradation can be much greater even though the mechanical loading is lesser. It was even possible to predict the fracture zone in the grips (Figure 11(b)), a phenomenon which was observed experimentally and which leads to major experimental problems [De Melo-Loseille and Lamon, 2009; Momon et al., 2010]. Thus, our model could be used as an experiment design tool in order to ensure that fracture would take place in the zone of interest of the specimen. Besides, this case illustrates the need to consider the whole structure for the lifetime study, if only because the fracture zone cannot always been determined a priori.

\section{Application to damage tolerance analysis}

In this section, we illustrate the application of our strategy to the damage tolerance analysis of structures, which is one of the

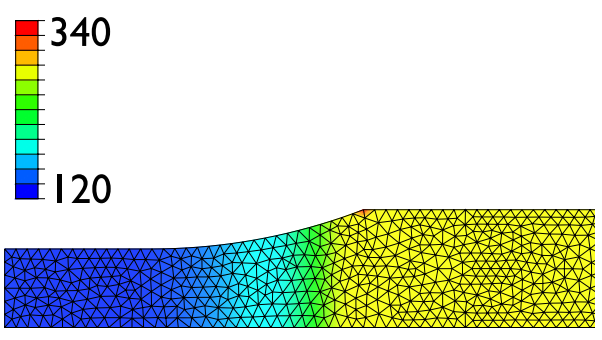

(a) $\mathrm{T}=500^{\circ} \mathrm{C}$

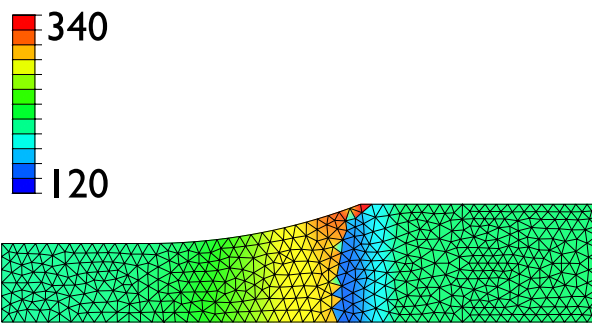

(b) $\mathrm{T}=700^{\circ} \mathrm{C}$

Figure 10: With a temperature gradient: the residual strength at two temperatures (200MPa loading for 278 hours)

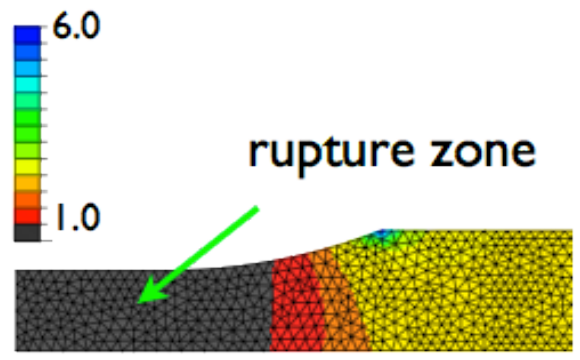

(a) $\mathrm{T}=500^{\circ} \mathrm{C}$

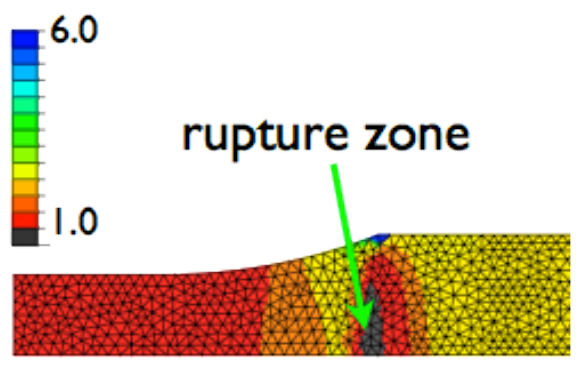

(b) $\mathrm{T}=700^{\circ} \mathrm{C}$

Figure 11: With a temperature gradient: the strength reserve factor at two temperatures (200MPa loading for 278 hours) 
main concerns associated with industrial developments [Herb et al., 2010; Bourgeon, 2010; Picard et al., 2010]. The objective is to characterize the influence of damaging impacts on the residual lifetime of structures.

According to experimental observations, classical quasistatic indentations generate cone-shaped damaged zones which can be approximated by cylindrical holes [Herb et al., 2010]. Let us consider the structural example of an open-hole specimen made of the same material and subjected to the same type of loading as the dog bone specimen of the previous section. Thus, this test case involves multiaxial stress fields and high stress gradients, especially near the hole. Figure 12 shows the geometry of the open-hole plate (with the FE mesh generated once again using GMSH[Geuzaine and Remacle, 2009]) subjected to tension loading in the $\mathrm{x}$-direction.

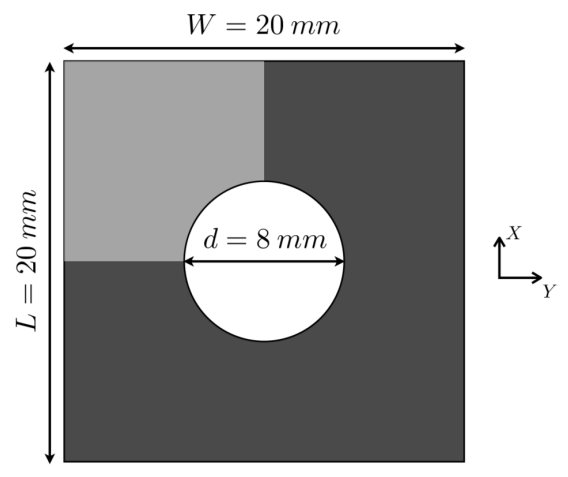

Figure 12: The geometry of the open-hole specimen subjected to tension loading in the $\mathrm{x}$-direction

\subsection{Predictions of the damage fields}

The model predicts that with an applied stress equal to $25 \mathrm{MPa}$ inter-yarn matrix cracks initiate around the hole, whereas with an applied stress equal to $55 \mathrm{MPa}$ intra-yarn matrix cracks initiate, also around the hole. Moreover, with an applied stress equal to 250MPa (Figure 13), the inter-yarn damage becomes saturated within the structure and intra-yarn matrix damage appears near the hole (Figures 13(b) and 13(c)). These predictions, which are consistent with the available experimental data, show that there is no unstable propagation of the damage leading to purely mechanical fracture of the specimen. Therefore, it is now necessary to address the damage tolerance problem associated with delayed fracture, which conditions the structure's lifetime.

\subsection{Lifetime predictions}

Figure 14 shows typical distributions of the indicator. In the uniform temperature case, the model predicts that at any temperature the strength degradation takes place mainly around the hole, where final fracture initiates.

In order to study the effect of the hole on the structure's lifetime, similar simulations were performed on plates with different hole diameters. The influence of the hole was measured

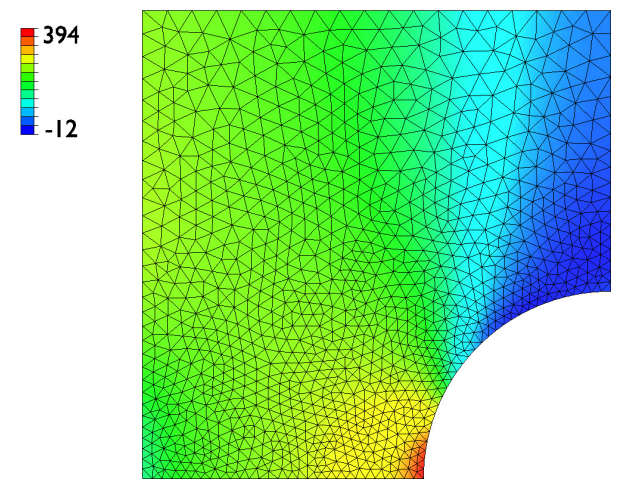

(a) Longitudinal stress $\sigma_{11}(\mathrm{MPa})$
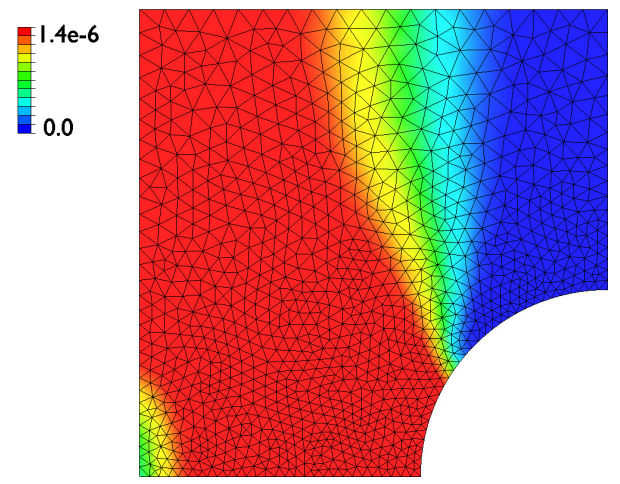

(b) Inter-yarn matrix damage $\alpha_{m}$ ( )

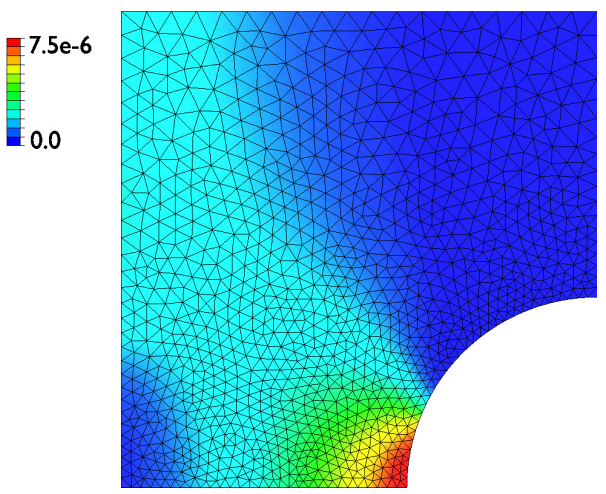

(c) Intra-yarn matrix longitudinal damage $\alpha_{f_{1}}$ ( )

Figure 13: The open-hole specimen under tension loading: (a) longitudinal stress, (b) inter-yarn matrix damage, (c) intra-yarn matrix damage 
by comparing the lifetimes of open-hole and dog bone specimens under the same effective stress (i.e. the same stress in the midplane of the plates). The results (Figure 15) indicate that the influence of the hole is greater at low macroscopic stress levels. Moreover, it appears that even under identical effective stresses large defects have more of an impact on the lifetime than small defects. Indeed, the damage zone is larger, which induces greater chemical degradation. It is important to note that this phenomenon, which is specific to lifetime analysis and does not exist in the case of strength analysis, is inherently part of our strategy, which illustrates its suitability for damage tolerance analysis in an industrial framework.

Also, in Figure 15, one should note that the ratio of the openhole stress (for a given hole) over the dog-bone stress (for a given lifetime) is almost constant. This constant is a stress concentration factor, not in the classical sense, but dedicated to delayed fracture. This stress concentration factor could be used by engineers as a very simple design tool.

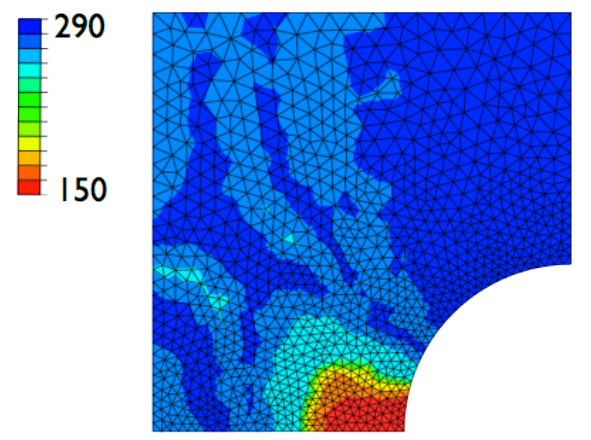

(a) $\sigma_{1}^{R}\left(t_{0}\right)(\mathrm{MPa})$

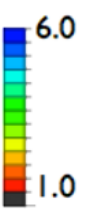

(b) $\tilde{\sigma}_{1}^{R}\left(t_{0}\right)$

Figure 14: The open-hole specimen subjected to tension loading: (a) residual strength, (b) strength reserve factor $\left(200 \mathrm{MPa}\right.$ loading at $500^{\circ} \mathrm{C}$ for $t_{0}=110$ hours)

\section{Conclusion}

In this paper, we presented and analyzed a strategy for the prediction of the lifetime of CMC structures. This strategy is a modified version of the strategy presented in [Cluzel et al., 2009]. Its originality lies in the possibility to perform lifetime predictions not only for single material points, but

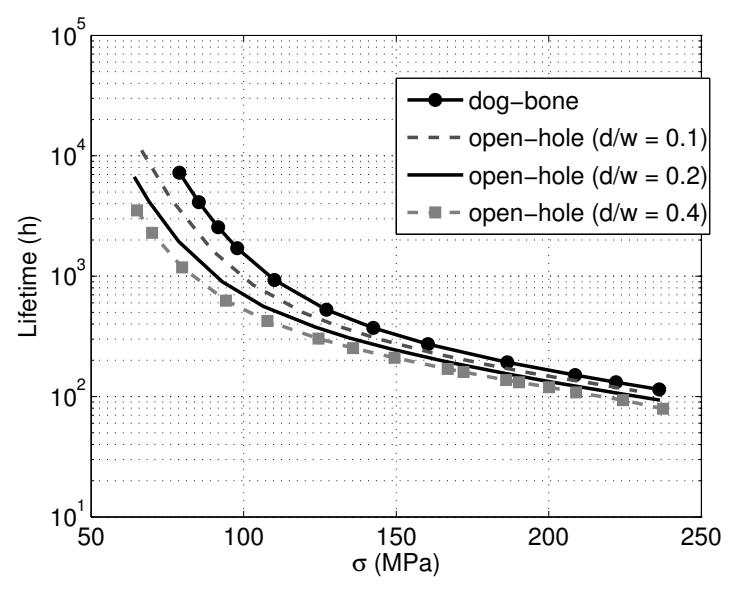

Figure 15: Damage tolerance analysis: the lifetime as a function of the effective stress at $500^{\circ} \mathrm{C}$ for several hole diameters

more generally for engineering structures. In order to do that, several elements had to be added to the strategy (e.g. a nonlocal fracture criterion); these have been presented here for the first time. Thus, it has now become possible to analyze the interaction of possibly heterogeneous stress and temperature fields in a complex structure.

The new strategy can be roughly summarized as follows: First, a mechanical damage model is applied to the structure using finite element analysis, leading to the prediction of the magnitude of each mechanical damage mechanism. Then, in a post-processing step, a physicochemical healing and damage model is applied at each material point of the structure, leading to the prediction of the strength degradation. Finally, a criterion based on nonlocal stresses and strength reserve factors is used in order to predict the structure's lifetime. It is important to note that the strategy presented here enables one not only to predict the structure's lifetime, but also to determine the fracture zone.

A first application to the calculation of dog bone specimens enabled us to gain confidence in the strategy. Indeed, since the strategy was derived from [Baranger et al., 2007; Cluzel et al., 2007, 2009], it was found to be compatible with experimental measurements of the structure's lifetime dependence on the applied stress and temperature. Also, the strategy made it possible to predict the structure's fracture zone for the first time, which represents an important step forward in the modeling of CMCs. For example, under specific conditions, fracture was predicted in the grip, which is consistent with experimental observations. This opens a very interesting perspective for the shape optimization of specimens for lifetime experiments and eventually, of course, for the optimization of real engineering structures.

The strategy was also applied to the damage tolerance analysis of structures, and calculations of open-hole specimens were given as examples. For instance, it was possible to predict the influence of the hole's diameter on the specimen's lifetime. Therefore, a potential application of the strategy would be the prediction of the residual lifetime of industrial structures after various types of damaging impacts. Systematic validation is 
underway in order to establish this capability.

Even though this paper has shown that the proposed strategy, as it exists today, performs well in the case of structural parts, it is clear that additional developments and validations are necessary. Work is in progress in that direction and will be presented in subsequent papers.

Moreover, the model itself needs to be improved in order to match the behavior of actual CMCs more closely. For example, in the mechanical part, the fiber breaking mechanism will be introduced, which will enable the prediction of both the initiation and the propagation of the macroscopic crack leading to the final fracture of the structure. This will make it possible to introduce a significant coupling between the mechanical and physicochemical parts of the model, with environmentinduced fiber rupture impacting the mechanical fields. Then, it will become possible to analyze the complex roles of mechanics and chemistry in the sequential fracture of tows until final fracture. Finally, concerning the physicochemical part, the fiber strength degradation model will be replaced by the model developed in [Ladevèze and Genet, 2010], which addresses the phenomenon's stress dependence and scattering naturally. This will enable one to study the significant variability of the lifetime of CMCs.

\section{Acknowledgment}

This work was carried out as part of the joint research program "Modeling-Extrapolation-Validation of the lifetime of composites with self-healing ceramic matrix" among SAFRAN-Snecma Propulsion Solide, the DGA, the CNRS, the CEAT, INSA Lyon, ENS Cachan, the University of Bordeaux and the University of Perpignan, and also as part of the ARCOCE mechanical research and technology program sponsored by Snecma Propulsion Solide and the Région Aquitaine.

\section{References}

Naslain R. Design, preparation and properties of non-oxide CMCs for application in engines and nuclear reactors: an overview. Composites Science and Technology2004;64(2):155-70. doi:10.1016/S0266-3538(03)00230-6. Symposium on Multifucntional Materials and Structures, Stuttgart, Germany, 16-20 032003.

Bourgeon M. Thermostructural materials in aerospace industry: applications and standardization. In: Proceedings of the 7th International Conference on High Temperature Ceramic Matrix Composites (HTCMC7). 2010,7th International Conference on High Tempurature Ceramic Matrix Composites (HTCMC7), Bayreuth, Germany, 20-22 092010.

Aveston J., Cooper G., Kelly A. Single and multiple fracture. In: Proceedings of the Conference of the National Physical Laboratory on the properties of fiber composites; vol. 4. 1971, p. 15-26.

Marshall D., Evans A. Failure mechanisms in ceramic-fiber ceramic-matrix composites. Journal of the American Ceramic Society1985;68:225-31.

Marshall D., Cox B., Evans A. The mechanics of matrix cracking in brittlematrix fiber composites. Acta Metallurgica1985;33(11):2013-21.

Guillaumat L., Lamon J. Probabilistic-statistical simulation of the non-linear mechanical behavior of a woven $\mathrm{SiC} / \mathrm{SiC}$ composite. Composites Science and Technology1996;56:803-8.

Lamon J. A micromechanics-based approach to the mechanical behavior of brittle-matrix composites. Composites Science and Technology2001;61:2259-72.
Gauthier W., Lamon J. Delayed Failure of Hi-Nicalon and Hi-Nicalon S Multifilament Tows and Single Filaments at Intermediate Temperatures (500$800^{\circ} \mathrm{C}$ ). Journal of the American Ceramic Society2009;92(3):702-9.

Gauthier W., Pailler F., Lamon J., Pailler R. Oxidation of Silicon Carbide Fibers During Static Fatigue in Air at Intermediate Temperatures. Journal of the American Ceramic Society2009;92(9):2067-73. doi:10.1111/j.15512916.2009.03180.x.

Ladevèze P., Genet M. A new approach to the subcritical cracking of ceramic fibers. Composites Science and Technology2010;70(11):1575-83.

Lamouroux F., Bertrand S., Pailler R., Naslain R., Cataldi M. Oxidationresistant carbon-fiber-reinforced ceramic-matrix composites. Composites Science and Technology1999;59(7):1073-85.

Naslain R., Pailler R., Bourrat X., Bertrand S., Heurtevent F., Dupel P., et al. Synthesis of highly tailored ceramic matrix composites by pressure-pulsed CVI. Solid State Ionic2001;141:541-8. XIVth International Symposium on the Reactivity of Solids (XIVth ISRS), Budapest, Hungary, AUG 27-31, 2000.

Cluzel C., Baranger E., Ladevèze P., Mouret A. Mechanical behaviour and lifetime modelling of self-healing ceramic-matrix composites subjected to thermomechanical loading in air. Composites Part A: Applied Science and Manufacturing2009;40:976-84. doi:10.1016/j.compositesa.2008.10.020. 15th French National Conference on Composites (JNC15), Marseille, France, 06-08 062007.

Ladevèze P., Letombe S., Cluzel C. A CMC damage model based on micro and macromechanics for high-temperature and complex loading. In: Proceedings of the 4th International Conference on High Temperature Ceramic Matrix Composites (HTCMC4). 2001,4th International Conference on High Tempurature Ceramic Matrix Composites (HTCMC4).

Cluzel C., Baranger E., Ladevèze P., Mouret A. Prediction of the lifetime of self-healing ceramic matrix composites: II - Analysis of cracking and oxydation mechanisms. In: Proceedings of the 15th National Conference on Composite Materials (JNC15) (in French). 2007, p. 885-94.

Baranger E., Cluzel C., Ladevèze P., Mouret A. Prediction of the lifetime of self-healing ceramic matrix composites: I - Macroscopic modeling of cracking (in French). In: Proceedings of the 15th National Conference on Composite Materials (JNC15) (in French). 2007,.

Ladevèze P., Letombe S. Recent advances on an anisotropic damage theory including unilateral effects. In: Proceedings of the International Bimestre on Damage Mechanics. Symposium on Continuous Damage and Fracture; 2000,

Ladevèze P. An anisotropic damage theory with unilateral effects: applications to laminate and three- and four-dimensional composites. In: Allix O., Hild F., editors. Continuum damage mechanics of materials and structures. Elsevier; 2002, p. 205-33.

Ladevèze P. On an anisotropic damage Theory (in French). Internal report34; LMT-Cachan; 1983.

Liu Y., Zhang L., Cheng L., Yang X.L.W., Zhang W., Xu Y., et al. Preparation and oxidation resistance of $2 \mathrm{~d}$ c/sic composites modified by partial boron carbide self-sealing matrix. Materials Science and Engineering Part A2008;498(1-2):430-6. doi:10.1016/j.msea.2008.08.022. International Conference on Recent Advances in Composite Materials (ICRACM 2007).

Tong C., Cheng L., Yin X., Zhang L., Xu Y. Oxidation behavior of $2 \mathrm{~d} \mathrm{c} / \mathrm{sic}$ composite modified by sib4 particles in inter-bundle pores. Composites Science and Technology2008;68(3-4):602-7. doi: 10.1016/j.compscitech.2007.10.016.

Liu Y., Cheng L., Zhang L., Yang W., Zhou S., Zhang W. Fracture behavior and mechanism of $2 \mathrm{~d}$ c/sic-bcx composite at room temperature. Materials Science and Engineering Part A2011;528(3):1436-41. doi: 10.1016/j.msea.2010.10.045.

Zhang C., Qiao S., Yan K., Liu Y., Wu Q., Han D., et al. Mechanical properties of a carbon fiber reinforced self-healing multilayered matrix composite at elevated temperatures. Materials Science and Engineering Part A2011;528(7-8):3073-8. doi:10.1016/j.msea.2011.01.009.

Mei H., Cheng L., Zhang L. Damage mechanisms of c/sic composites subjected to constant load and thermal cycling in oxidizing atmosphere. Scripta Materialia2006;54(2):163-8. doi:10.1016/j.scriptamat.2005.09.044.

Mei H., Cheng L. Stress-dependence and time-dependence of the postfatigue tensile behavior of carbon fiber reinforced sic matrix composites. Composites Science and Technology2011;71(11):1404-9. doi: 10.1016/j.compscitech.2011.05.013.

Cox B., Yang Q. In Quest of Virtual Tests for Structural Composites. 
Science2006;314(17):1102-7. doi:10.1126/science.1131624.

Aubard X., Cluzel C., Guitard L., Ladevèze P. Modelling of the mechanical behaviour of 4D carbon/carbon composite materials. Composites Science and Technology 1998;58(5):701-8. doi:10.1016/S0266-3538(97)00181-4. 10th French National Conference on Composite Materials (JNC10), Paris, France, 29-31 101996.

Gasser A., Ladevèze P., Poss M. Damage mechanisms of a woven $\mathrm{SiC} / \mathrm{SiC}$ composite: modelling and identification. Composites Science and Technology 1996;56:779-84.

Desmorat R., Gatuingt F., Ragueneau F. Nonlocal anisotropic damage model and related computational aspects for quasi-brittle materials. Engineering Fracture Mechanics2007;74(10):1539-60. doi: 10.1016/j.engfracmech.2006.09.012.

Lesne P., Saanouni K. Modeling of irreversible damage-induced strains in brittle elastic composites. Recherche Aérospatiale1993;(2):23-37.

Voyiadjis G., Kattan P. Damage of fiber-reinforced composite-materials with micromechanical characterization. International Journal of Solids and Structures 1993;30(20):2757-78.

Pensée V., Kondo D., Dormieux L. Micromechanical analysis of anisotropic damage in brittle materials. Journal of Engineering Mechanics2002;128(8):889-97. doi:10.1061/(ASCE)07339399(2002)128:8(889). Conference on Mechanics and Materials, SAN DIEGO, CALIFORNIA, 2001

Chaboche J., Maire J. A new micromechanics based CDM model and its application to CMC's. Aerospace Science and Technology2002;6(2):13145. doi:doi:10.1016/S1270-9638(02)01154-9.

Marcin L., Maire J., Carrère N., Martin E. Development of a macroscopic damage model for woven ceramic matrix composites. International Journal of Damage Mechanics2010; In Press, Accepted Manuscript.

Letombe S. Modelling of the damage/oxydation coupling in ceramic matrix composites (in French). Phd thesis; ENS-Cachan (France); 2005.

Baranger E., Cluzel C., Ladevèze P., Mouret A. Identification and validation of a multi-physic macro model for the lifetime prediction of self-healing ceramic matrix composites. In: Proceedings of the 13th European Conference on Composite Materials (ECCM13). 2008,

Whitney R., Nuismer J. Stress fracture criteria for laminated composite laminates containing stress concentrations. Journal of Composite Materials 1974;8:253-65.

Nuismer J., Whitney R. Uniaxial failure of composite failure laminates containing stress concentrations. Fracture Mechanics of Composites1975;:117_ 42.

Hochard C., Lahellec N., Bordreuil C. A ply scale non-local fibre rupture criterion for CFRP woven ply laminated structures. Composite Structures2007;80(3):321-6. doi:10.1016/j.compstruct.2006.05.021.

Miot S., Hochard C., Lahellec N. A non-local criterion for modelling unbalanced woven ply laminates with stress concentrations. Composite Structures2010;92(7):1574-80. doi:10.1016/j.compstruct.2009.11.019.

Flores S., Evans A., Zok F., Genet M., Cox B., Marshall D., et al. Treating matrix nonlinearity in the binary model formulation for 3D ceramic composite structures. Composites Part A: Applied Science and Manufacturing2010;41(2):222-9. doi:DOI: 10.1016/j.compositesa.2009.10.020.

Department of Defence Composite Materials Handbook. Volume 5. Ceramic Matrix Composites; Department of Defence, USA; 2002.

Rouby D., Reynaud P. Fatigue behaviour related to interface modification during load cycling in ceramic matrix fibre composites. Composites Science and Technology 1993;48:109-18.

Evans A., Zok F., McMeeking R. Fatigue of ceramic matrix composites. Acta Metallurgica et Materialia1995;43:859-75.

Quemard L., Rebillat F., Guette A., Tawil H., Louchet-Pouillerie C. Degradation mechanisms of a SiC fiber reinforced self-sealing matrix composite in simulated combustor environments. Journal of the European Ceramic Society2007;27(4):2085-94.

Rebillat F., Martin X., Guette A. Kinetic oxidation laws of boron carbide in dry and wet environments. In: Proceedings of the 5th International Conference on High Temperature Ceramic Matrix Composites (HTCMC5). 2004, p. 321-6.

Garitte E., Rebillat F., Guette A. B4C as the precursor of the healing in a $\mathrm{SiC} / \mathrm{SiC}$ composite : behaviour under wet atmosphere. In: Proceedings of the 12th European Conference on Composite Materials (ECCM12). 2006,

Laforêt A., Lamon J. Static fatigue of multifilament tows at high tempera- tures above $900^{\circ} \mathrm{C}$. In: Proceedings of the 13 th European Conference on Composite Materials (ECCM13). 2008,.

Ladevèze P. Nonlinear Computational Structural Mechanics: New Approaches and Non-Incremental Methods of Calculation. Mechanical Engineering; Springer; 1999. Translated by James G. Simmonds.

Passieux J., Ladevèze P., Néron D. A scalable time-space multiscale domain decomposition method: adaptive time scale separation. Computational Mechanics2010;46(4):621-33. doi:10.1007/s00466-010-0504-2.

Kerfriden P., Allix O., Gosselet P. A three-scale domain decomposition method for the 3D analysis of debonding in laminates. Computational Mechanics2009;44(3):343-62. doi:10.1007/s00466-009-0378-3.

Leclerc $\mathrm{H}$. Towards a no compromise approach between modularity, versatility and execution speed for computational mechanics on CPUs and GPUs. In: Proceedings of the 4th European Congress on Computational Mechanics (ECCM2010). 2010,

Genet M., Marcin L., Ladevèze P. On structural computations until fracture based on an anisotropic and unilateral damage theory. Submitted to International Journal of Damage Mechanics2011;

Geuzaine C., Remacle J. Gmsh: a three-dimensional finite element mesh generator with built-in pre- and post-processing facilities. International Journal for Numerical Methods in Engineering2009;79(11):1309-31.

De Melo-Loseille O., Lamon J. Prediction of Ceramic Matrix Composites Lifetime in High Temperature Static Fatigue based on a Probabilistic Fracture Mechanics Model. In: Proceedings of the 17th International Conference on Composite Materials (ICCM17). 2009,.

Penas O. Study of $\mathrm{SiC} / \mathrm{SiBC}$ multi-layered matrix composites in cyclic fatigue at high temperature under air (in French). Phd thesis; INSA-Lyon (France); 2002.

Moevus M. Damage mechanisms, acoustic emission and lifetime in static fatigue of $\mathrm{SiC} / \mathrm{Si}-\mathrm{B}-\mathrm{C}$ comsposites at intermediate temperature $\left(; 800^{\circ} \mathrm{C}\right)$ (in French). Phd thesis; INSA-Lyon (France); 2007.

Momon S., Moevus M., Godin N., R'Mili M., Reynaud P., Fantozzi G., et al. Acoustic emission and lifetime prediction during static fatigue tests on ceramic-matrix-composite at high temperature under air. Composites Part A: Applied Science and Manufacturing2010;41(7):913-8. doi: 10.1016/j.compositesa.2010.03.008.

Herb V., Couégnat G., Martin E. Damage assessment of thin sic/sic composite plates subjected to quasi-static indentation loading. Composites Part A: Applied Science and Manufacturing2010;In Press, Accepted Manuscript. doi:DOI: 10.1016/j.compositesa.2010.08.004

Picard M., Reynaud P., R'Mili M., Fantozzi G., Godin N., Diss P. Notch sensitivity of CMC during creep and tensile tests at Picardintermediate temperature. In: Proceedings of the 7th International Conference on High Temperature Ceramic Matrix Composites (HTCMC7). 2010,7th International Conference on High Tempurature Ceramic Matrix Composites (HTCMC7), Bayreuth, Germany, 20-22 092010. 